\title{
Análise da interação entre os eventos pluviométricos e ações antrópicas como agentes deflagradores de deslizamentos na Zona Norte do Recife
}

Analysis of the interaction between pluviometric events and anthropic actions as trigger landslides agents in the Northern Zone of Recife

\author{
SILVA $^{1}$, F. A. A.; BARBOSA ${ }^{2}$, B. G. S.; DUARTE ${ }^{3}$, C. C. \\ rbdart@gmail.com
}

\section{Resumo}

Em função das características climáticas do município do Recife e de seus fatores físico-naturais, as chuvas, representam de modo geral, um agente deflagrador de maior influência dos deslizamentos na cidade. O Distúrbio Ondulatório de Leste (DOL), que atua de abril a julho, é o principal sistema responsável pela intensificação das chuvas nesse período. As ações antrópicas, por sua vez, atuam como um agente efetivo preparatório, diminuindo o fator de segurança das encostas, já suscetíveis a deslizamentos como as dos Tabuleiros e Colinas da Zona Norte do Recife. Assim, a presente pesquisa tem como objetivo analisar e demonstrar a atuação das ações antrópicas como principal agente deflagrador dos movimentos de massa associados aos eventos extremos de chuva na Cidade do Recife, com ênfase nos bairros da Zona Norte e no ano de 2017.

Palavras-Chave: Eventos extremos, agentes deflagradores, movimentos de massa.

\begin{abstract}
Due to the climatic characteristics of the city of Recife and its physical-natural factors, rainfall generally represents a triggering agent of greater influence of the landslides in the city. The East Undulatory Disorder (EUD), which operates from April to July, is the main system responsible for the intensification of rainfall in this period. The anthropic actions, in turn, act as an effective preparatory agent, decreasing the safety factor of the slopes, already susceptible to landslides such as those of the Tracks and Hills of the North Zone of Recife. Thus, the present research has the objective of analyzing and demonstrating the anthropic actions as the main agent for the mass movements associated with extreme rainfall events in the city of Recife, with emphasis on the districts of the North Zone and the year 2017.
\end{abstract}

Keywords: Extrem events, triggering agent, mass movements.

\section{INTRODUÇÃ̃O}

O processo de urbanização no Brasil teve início na década de 1940, passando por uma aceleração na década de 1970 com o êxodo rural (migração em massa da população das áreas rurais para as cidades). Esse processo de migração intensificou o adensamento populacional

${ }^{I}$ Fernando Arthur Alves da Silva, Departamento de Ciências Geográficas, Universidade Federal de Pernambuco, Recife-PE, Brasil.

${ }^{2}$ Bárbara Gabrielly Silva Barbosa, Departamento de Ciências Geográficas, Universidade Federal de Pernambuco, RecifePE, Brasil.

${ }^{3}$ Cristiana Coutinho Duarte, Departamento de Ciências Geográficas, Universidade Federal de Pernambuco, Recife-PE, Brasil. 
nas periferias dos centros urbanos, o qual não foi seguido por um planejamento e implementação de infraestrutura necessária a fluidez urbana. Ademais, a alta especulação imobiliária das áreas destinadas à habitação, levou uma grande parcela da população a construir suas casas de forma irregular em áreas inapropriadas, como as áreas de risco a processos geodinâmicos, deslizamentos (áreas de morros) e inundação (margens de rios).

Algumas dessas áreas passaram por um processo de requalificação urbana. Entretanto, até a implementação efetiva da infraestrutura que determine uma área como urbanizada, vários processos geodinâmicos (deslizamentos, inundações e alagamentos) podem ocorrer, principalmente quando há um evento de chuva intensa.

O processo de ocupação da cidade do Recife, capital do estado de Pernambuco, não foi diferente. Suas características físico-naturais como: planície costeira a leste e colinas sobre a Formação Barreiras na porção norte e sul e sobre o embasamento cristalino na porção oeste; indicam uma suscetibilidade natural a inundações/alagamentos e deslizamentos, respectivamente. Somando-se a essas características, têm-se as intervenções antrópicas indevidas, no processo de ocupação espontânea e desordenada dessas áreas, intensificando, assim, o surgimento de áreas de riscos naturais.

Guidicine e Nieble (1984) classificam os condicionantes dos deslizamentos como agentes e causas de instabilização. Entende-se por causa, o modo de atuação de um determinado agente, ou seja, um agente pode expressar-se por uma ou mais causas. Por sua vez os agentes podem ser classificados com predisponentes e agentes efetivos. Os primeiros referem-se a um conjunto de características naturais intrínsecas do terreno, sem a ação do homem, como por exemplo: geologia, morfologia (declividade, forma da encosta), aspectos climático-hidrológico, etc.

Os agentes efetivos representam o conjunto de elementos diretamente responsáveis pelo desencadeamento dos movimentos de massa, nesses estão incluídas as ações humanas. Em virtude de sua forma de participação, são divididos em preparatório e imediatos. As ações humanas podem atuar ora como agentes efetivos preparatório ora como imediato. Os agentes efetivos imediatos pode ser definido também como deflagradores.

As águas, sejam elas provenientes das chuvas, ou servidas, representam de modo geral um agente efetivo preparatório ou imediato de maior influência nos movimentos de massa na Região Metropolitana do Recife (COUTINHO; BANDEIRA, 2012).

De acordo com o Plano Municipal de Redução de Risco da cidade do Recife, existem cerca de 470.000 habitantes em áreas de morros, destes 10.374 vivem em locais de risco alto 
ou muito alto, com 140 áreas de risco a escorregamentos distribuídas pelo município (PMRR, 2006).

Diante da supracitada problemática, a presente pesquisa tem como objetivo analisar e demonstrar a atuação das ações antrópicas como principal agente deflagrador dos movimentos de massa associados aos eventos extremos de chuva na cidade do Recife, com ênfase nos bairros da Zona Norte. Para tanto, foram delineados os seguintes objetivos específicos: analisar o comportamento pluviométrico no ano de 2017, com a identificação dos sistemas meteorológicos atuantes e a interação da chuva antecedente a ocorrência dos deslizamentos; identificar e descrever as intervenções antrópicas que atuaram como agentes efetivos preparatório ou imediato dos deslizamentos.

A justificativa da realização deste trabalho foi em função da ocorrência de deslizamentos, com vítimas fatais, fora do período chuvoso do município (abril a julho) no ano de 2017, com maior destaque para os bairros de Macaxeira, Nova Descoberta e Dois Unidos (Zona Norte do Recife).

\section{METODOLOGIA}

\subsection{Localização e breve caracterização da área de estudo}

A área de estudo compreende a Zona Norte da Cidade do Recife, região onde ficam localizados os bairros da Macaxeira, Nova Descoberta e Dois Unidos (Figura 1).

A cidade do Recife assim como toda Zona da Mata apresenta uma característica chuvosa singular de todo o estado, suas chuvas são distribuídas entre os períodos de outonoinverno do hemisfério sul, com pluviometria média anual de $2.307,5 \mathrm{~mm}$, caracterizando um clima Tropical Litorâneo do Nordeste Oriental, o qual também diferencia dos demais climas mais secos do resto do Nordeste do Brasil (MENDONÇA; DANI-OLIVEIRA, 2007).

Os sistemas atmosféricos atuantes na porção leste do Nordeste do Brasil são, de macro a microescala: a Zona de Convergência Intertropical (ZCIT), Distúrbios Ondulatórios de Leste (DOL’s), Vórtice Ciclônico em Altos Níveis (VCAN), Sistemas Frontais (SF); Linhas de Instabilidade (LI), Sistemas Convectivos de Mesoescala (SCM), tempestades isoladas e circulação de brisas (MOLION E BERNARDO, 2002). Dentre os referidos sistemas a atuação dos Distúrbios Ondulatórios de Leste (DOLs) produzidos por penetração dos sistemas frontais no Atlântico, são responsáveis por 30\% a 40\% das chuvas nessa região, levando aos máximos mensais de maio a julho, associados também a uma maior atuação das brisas nesse período (CHOU, 1990; SILVA, 2010). 


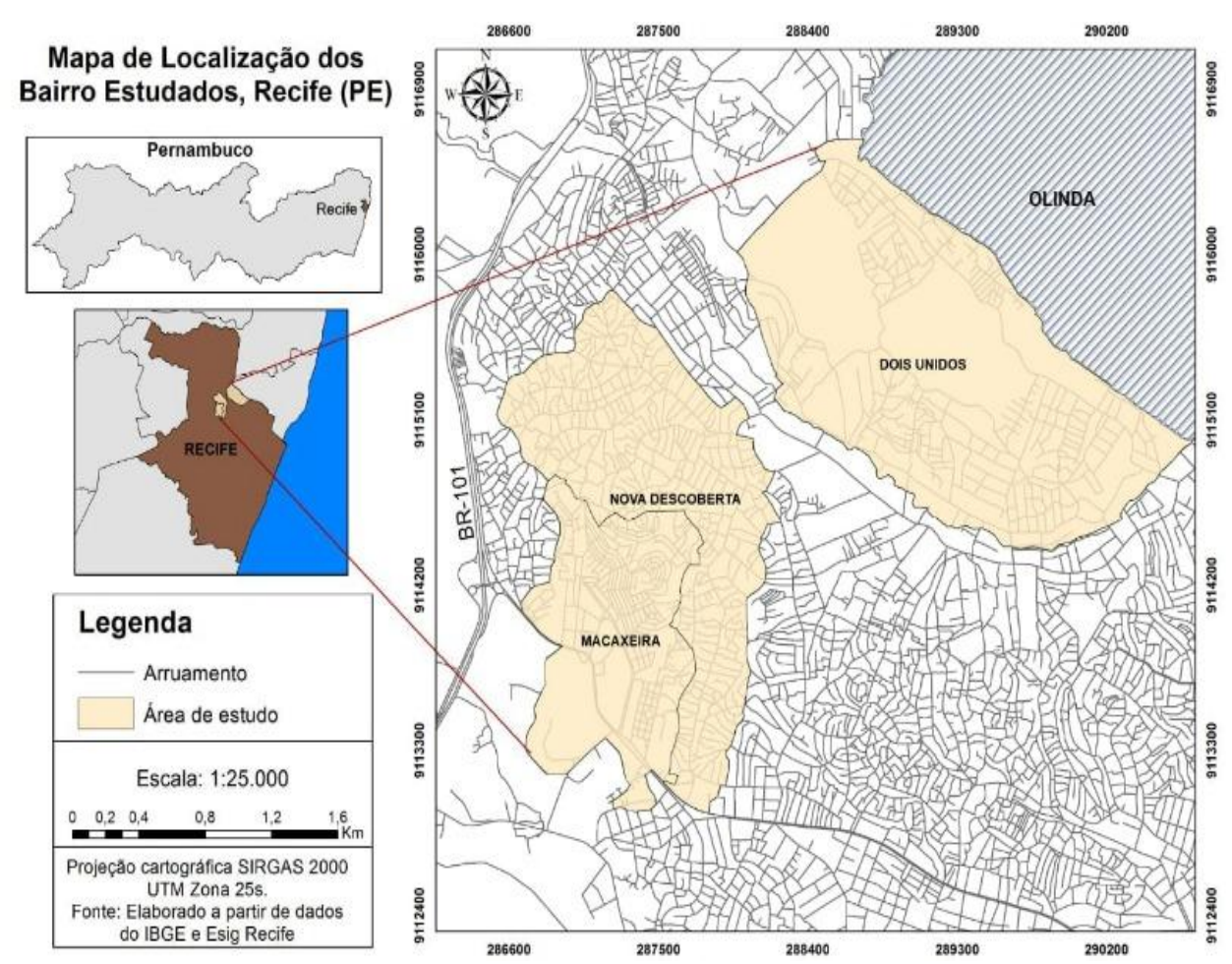

Figura 1: Mapa de localização da área de estudo. Fonte: IBGE; ESIG (Prefeitura da Cidade do Recife).

O município do Recife possui uma população de aproximadamente 1,5 milhões de habitantes, segundo o Programa das Nações Unidas para o Desenvolvimento (PNUD, 2010). O município do Recife atingiu 100\% de sua capacidade urbanística no ano de 2010, ou seja, expandiu-se de tal maneira que possibilitou o povoamento em áreas de suscetibilidade natural a processos geodinâmicos.

Com relação a renda, desigualdade e pobreza dos habitantes do município, evidenciouse um crescimento econômico que proporcionou uma redução no número de pessoas extremamente pobres, atribuindo o percentual de apenas $4,77 \%$ da população recifense. Juntamente com a ascensão urbana, o município atingiu uma boa margem percentual para distribuição de água encanada, coleta de lixo e energia elétrica, como mostrado na tabela a seguir: 
Tabela 1 - Indicador da distribuição de serviços básicos nos bairros do Recife-PE.

\begin{tabular}{|l|l|l|l|}
\hline Indicadores de Habitação - Município - Recife - PE & 1991 & $\mathbf{2 0 0 0}$ & $\mathbf{2 0 1 0}$ \\
\hline \% da população em domicílios com água encanada & & & \\
\hline \% da população em domicílios com energia elétrica & 80,24 & 87,46 & 97,45 \\
\hline \% da população em domicílios com coleta de lixo & 99,77 & 99,92 & 99,92 \\
\hline
\end{tabular}

Fonte: Atlas de Desenvolvimento Humano/PNUD.

Os bairros em estudo localizam-se em uma área formada por colinas desenvolvidas sobre a Formação Barreiras. Essa formação é constituída de sedimentos de granulometria variada, caracterizado por uma mistura de areias e argilas, com horizontes de seixos subhorizontais, levemente direcionados para o mar na forma de tabuleiros elevados. De acordo com Galvão (2014) a mistura desses sedimentos nos morros da Zona Norte resulta em uma suscetibilidade a erosão menor do que nos morros sobre a Formação Barreiras da Zona Sul, onde o solo é mais friável, mais arenoso, com maior ocorrência de voçorocas. No entanto, a maior presença de argila nos morros da Zona Norte, torna-se essa região mais suscetível aos deslizamentos.

As mencionadas características refletem numa maior frequência de deslizamentos nos bairros da zona norte do Recife nos anos de 2015, 2016 e 2017, como por exemplo, Nova Descoberta, Dois Unidos e Guabiraba (Figura 2).

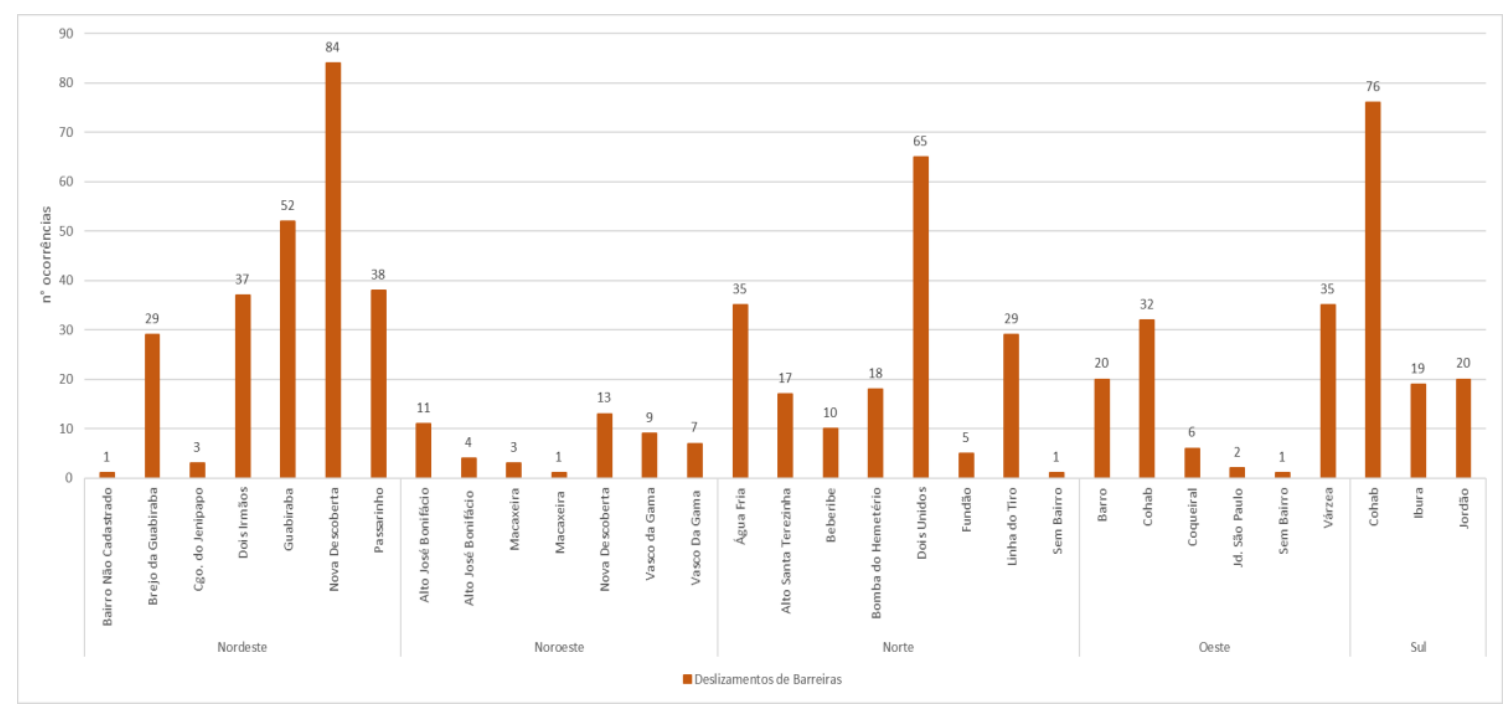

Figura 2: Bairros atingidos por deslizamento e alagamentos nos anos de 2015 a 2017. Fonte: Coordenadoria de Defesa Civil do Recife. 
Segundo Alheiros et al. (2004), o município é composto, em relação a sua área territorial, de aproximadamente $65 \%$ de áreas de morros. Dessa forma, os altos índices de deslizamentos no Recife, principalmente nos setores norte, noroeste e nordeste, do município, podem ser justificados pela sua configuração geomorfológica propícias a tais ocorrências e que são intensificadas pelas ações antrópicas indevidas.

\subsection{Procedimentos metodológicos}

Seguindo o que foi proposto nos objetivos, primeiramente foram coletados dados pluviométricos, mensais e diários, da estação do Alto da Brasileira no banco de dados da Agência Pernambucana de Águas e Clima - APAC. Analisou-se o comportamento pluviométrico da série histórica de 1999 a 2017 e os dados diários dos meses de maio e julho.

A escolha do ano de 2017 foi em função da série histórica da planilha de ocorrências fornecidas pela Coordenadoria de Defesa Civil de Recife (CODECIR). E, conforme será mostrado nos resultados foi o ano que apresentou o menor número de ocorrências, para facilitar a relação dos agentes efetivos preparatórios e imediatos como a chuva e as intervenções antrópicas. Foram analisadas somente as ocorrências efetivas de deslizamentos ou processos/atividades correlatas, para identificação dos bairros mais impactados, bem como os anos de maior número de ocorrências

Para a análise dos sistemas meteorológicos atuantes no município, nos meses de maio e julho de 2017 foram coletadas imagens do Satélite GOES (Geostationary Operational Environmental Satellite) no site do CPTEC/INPE (Centro de Previsão de Tempo e Estudos Climático/Instituto Nacional de Pesquisas Espaciais).

\section{RESULTADOS E DISCUSSÃO}

Tomando-se como base os dados do pluviômetro do Bairro do Alto da Brasileira, obtidos no banco de dados da APAC, verificou-se que o ano de 2017 apresentou um total pluviométrico de $1.590 \mathrm{~mm}$, abaixo da média histórica anual $(1.742 \mathrm{~mm})$. As chuvas foram concentradas nos meses de abril a julho, com destaque para o mês de julho. O qual esteve acima da média histórica.

Com base nos dados da Defesa Civil do município do Recife, o ano de 2017, dentre os anos analisados $(2015,2016$ e 2017) foi o que apresentou um menor quantitativo de eventos, obedecendo também o acumulado anual e a presença de chuvas extremas que ocorreram nesses anos (Figura 3). As ocorrências de deslizamentos nesse ano foram mais frequentes nos 
meses de abril, maio, junho e julho, com destaque para os meses de julho e maio, os quais serão detalhados a seguir.

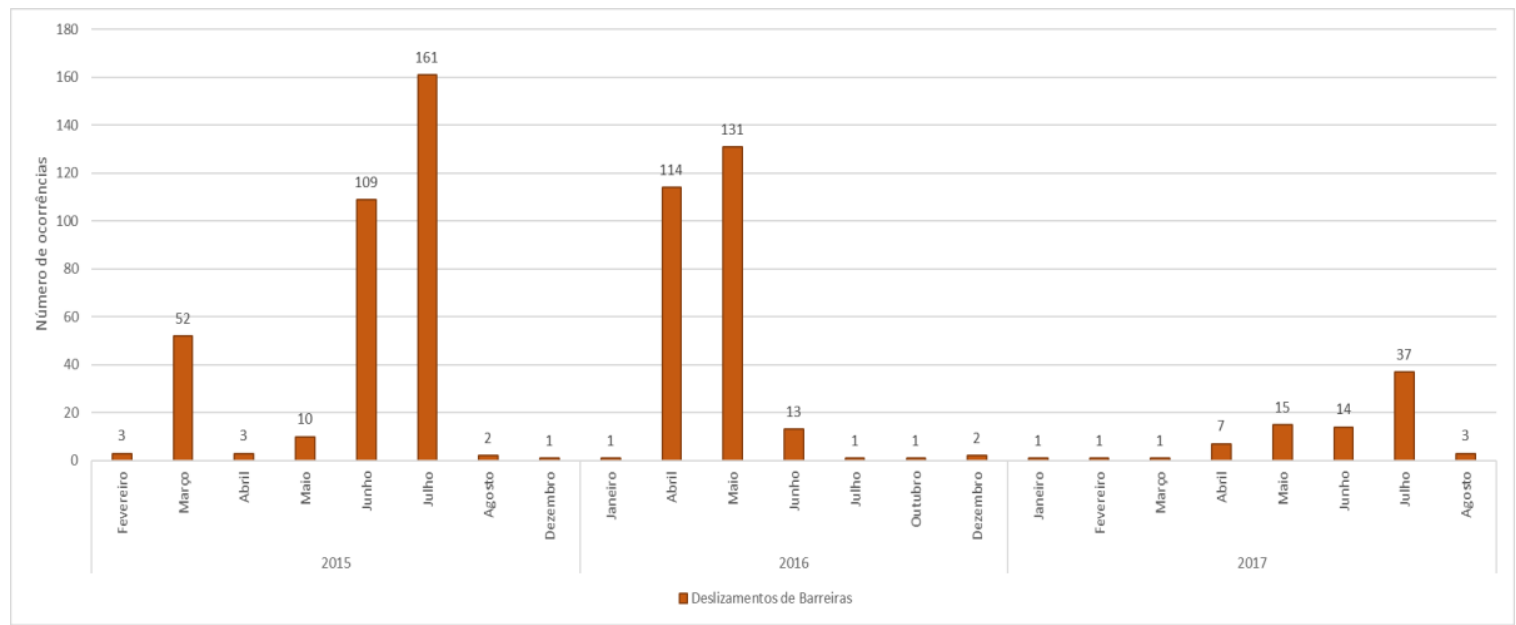

Figura 3: Distribuição do número de ocorrências de deslizamento por mês para os anos de 2015, 2016 e 2017 na cidade do Recife. Fonte: Gráfico elaborado pelos autores. Dados: COECIR

As chuvas do mês de maio concentraram-se nos dias 28, 29 e 30 desse mês representando um acumulado de $94 \mathrm{~mm} / 72 \mathrm{~h}$, concentrando no dia $29 \mathrm{com} 70,5 \mathrm{~mm} / 24 \mathrm{~h}$. Nesse mês, foram identificados dois deslizamentos no dia 29 e 9 no dia 31. A chuva antecedente ao dia 31 foi suficiente para a saturação do solo que foi agravada pela ação antrópica no local, atuando como um agente preparatório, por meio do corte de taludes e lançamento de águas servidas e lixo encosta abaixo (Figura 4).

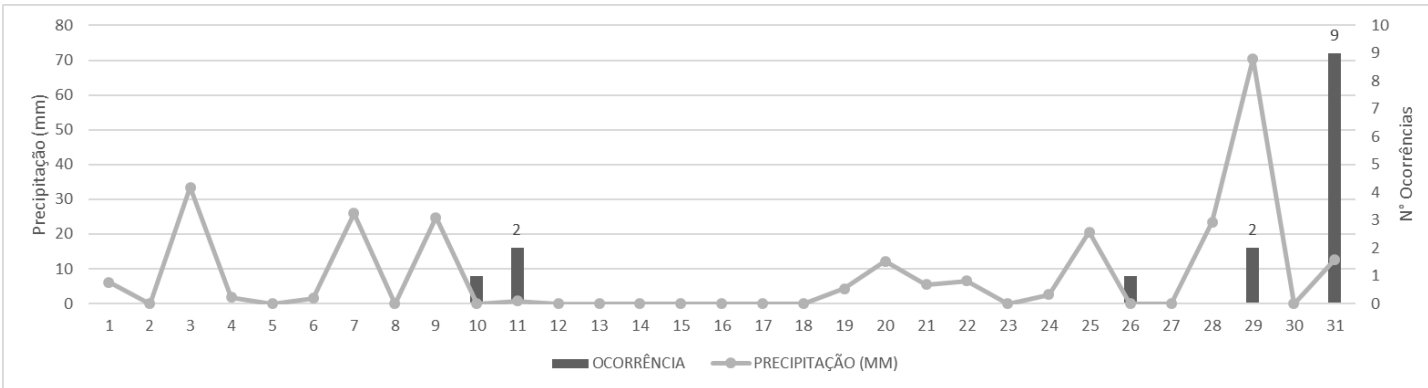

Figura 4: Relação entre os acumulados de chuva (24h) e o número de ocorrências de deslizamentos no mês de maio de 2017. Fonte: Gráfico elaborado pelos autores. Dados: COECIR e APAC.

As chuvas desse mês de maio foram geradas devido a atuação de dois eventos meteorológicos, a confluência e intensificação dos ventos úmidos nos baixos níveis da atmosfera e os Distúrbios Ondulatórios de Leste (DOL's) que ficou localizado mais acima, segundo o boletim mensal da APAC. 
Mesmo com pequenas obras para o escoamento da água superficial, bem como a presença de tubulações da Compesa para o fornecimento de água às casas do bairro Alto do Capitão, algumas dessas estruturas encontram-se entupidas por causa de uma grande presença de lixo lançado pela população (Figura 5). Nesse exemplo específico, o entupimento, levou ao rompimento e vazamento da tubulação intensificando a saturação do solo.
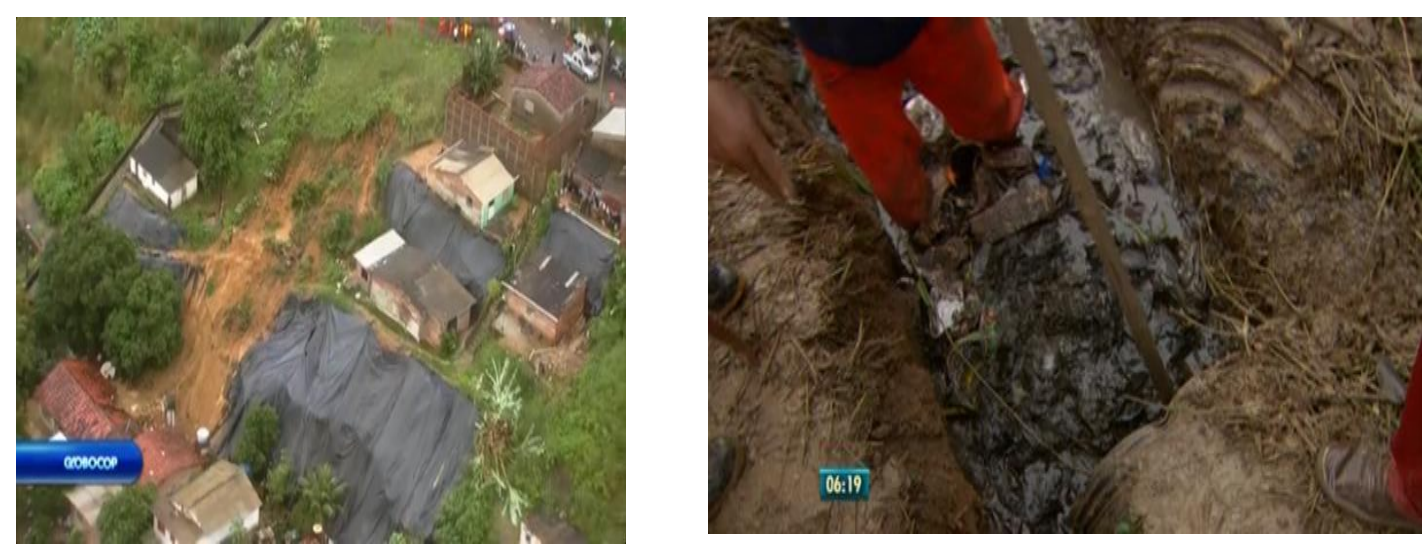

Figura 5: Imagens com o exemplo do deslizamento ocorrido no dia 31 de maio de 2017 no bairro (A) e tubulação entupida com lixo, que gerou o rompimento e intensificação do escoamento da água (B). Fonte: G1

Entre os dias 20 a 23 de julho, verificou-se um acumulado de 143,7 mm em 96 horas. Os deslizamentos foram distribuídos na seguinte forma: 7 e 8 deslizamentos nos dias 6 e 7 de julho, provavelmente, ocasionados pelas chuvas acumuladas no final do mês de junho; 3 e 7 nos dias 21 e 22 de julho. No dia 21 de julho, registrou um acumulado de chuva de 83,1 mm, o que pode ter desencadeado os deslizamentos dos dias 21 a 29 desse mês (Figura 6).

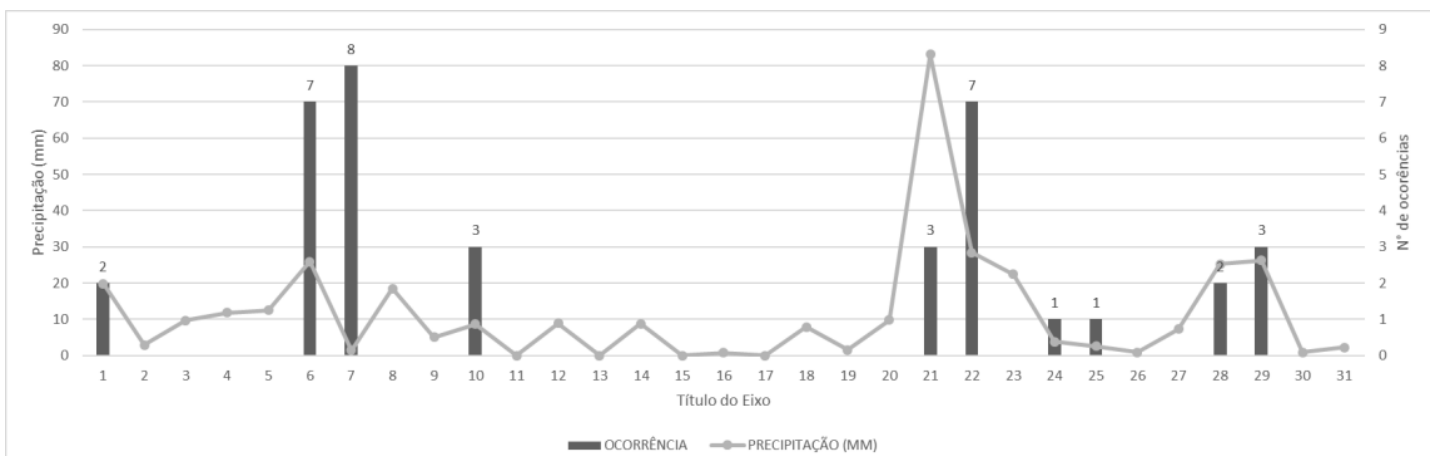

Figura 6: Relação entre os acumulados de chuva (24h) e o número de ocorrências de deslizamentos no mês de julho de 2017. Fonte: Gráfico elaborado pelos autores. Dados: COECIR e APAC.

Assim como as chuvas que ocorreram no mês de maio, no mês de julho, na madrugada entre os dias 20 e 21, foi intensificada a atuação de um DOLs da região, conforme a figura 7.

Até o momento, as ocorrências de deslizamentos analisadas na cidade do Recife, estiveram de acordo com o acumulado de precipitação acima de $94 \mathrm{~mm}$ em 72 horas. O 
aumento do número de deslizamento para o município é esperado durante o período chuvoso. No entanto, no ano de 2017, foi verificado um deslizamento no dia 26/09/2017 no bairro da Macaxeira, com um acumulado de 2,9 mm/24h, insuficiente para saturar o solo e deflagrar o deslizamento. Neste caso específico, a ação antrópica foi o principal deflagrador do movimento de massa. $\mathrm{O}$ uso indevido de maquinários sem as medidas corretas de engenharia, em uma área que não era considerada de risco, levaram a ocorrência de um deslizamento e a óbito um senhor que estava trabalhando na obra.

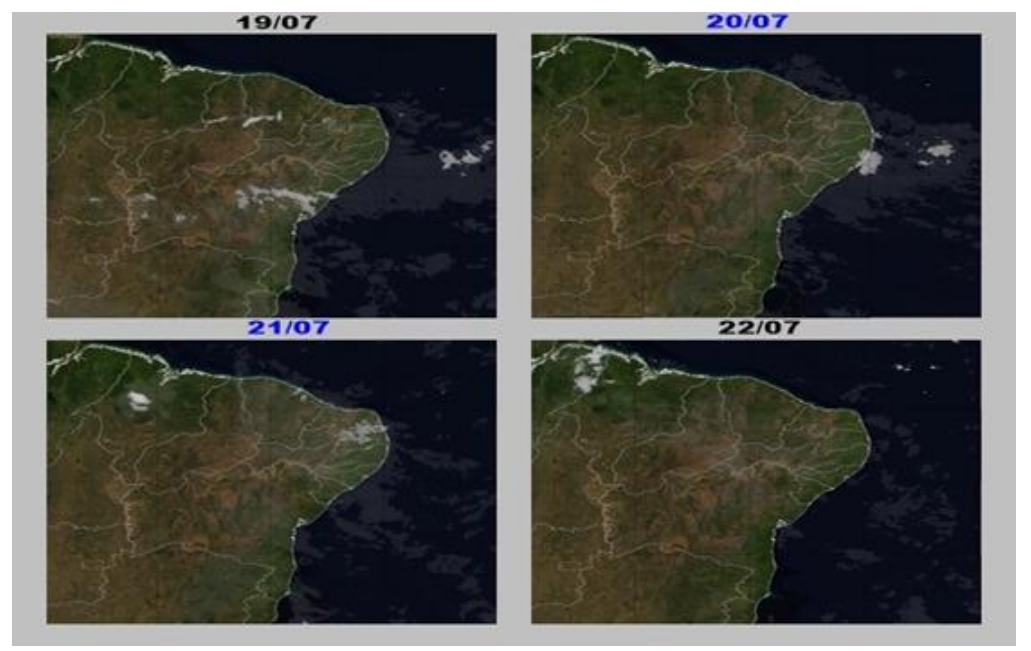

Figura 7: Imagens de satélite (GOES-13) 12:00 UTM.

\section{CONSIDERAÇÕES FINAIS}

Conforme foi visto, os bairros mais atingidos por deslizamentos no município do Recife são os bairros da Zona Norte, Nordeste e Noroeste, caracterizados por Tabuleiros e Colinas sobre a Formação Barreiras, o que infere aspectos geológicos, geomorfológicos e pedológicos como fatores predisponentes a ocorrência de deslizamentos na região.

Ademias, o adensamento populacional, a ocupação desordenada e inicialmente irregular dessas áreas, sem a implementação, em algumas áreas, de infraestrutura urbana, levam a ações, tais como: cortes verticalizados, aterros mal compactados, taludes desprovidos de cobertura superficial, lançamento de água servidas direta ou por rompimento de tubulações e acúmulo de lixo; que atuam como agentes efetivos preparatórios e imediatos de deslizamentos. Esse fato, gera uma dificuldade em se identificar um limiar de chuva que deflagre um movimento de massa nessa região.

O ano de 2017 foi o ano que apresentou um menor número de ocorrências de deslizamentos no município do Recife, dentre os anos de 2015, 2016 e 2017, acompanhando o comportamento pluviométrico em que esteve abaixo da média anual de precipitação pluvial 
para a série histórica de 1999 a 2017. Ainda seguindo o comportamento natural do aumento do número de ocorrência de deslizamentos no período chuvoso, principalmente sob a atuação de um Distúrbio Ondulatório de Leste (DOL), o ano de 2017 apresentou uma maior concentração de deslizamentos nos meses de maio e julho, períodos em que apresentaram somente um dia de chuva acumulada acima de $60 \mathrm{~mm} / 24 \mathrm{~h}$.

Contudo, o presente trabalho tratou-se de um estudo preliminar da relação entre o comportamento pluviométrico do município associado às ações antrópicas como principais agentes efetivos preparatórios e imediatos dos deslizamentos. A ação antrópica atua, como principal agravante nessa relação, uma vez que este fenômeno pode ser controlado, por meio de intervenções estruturais efetivas e não paliativas para a diminuição das áreas de risco da cidade. Além de ações educativas e de conscientização da população visando uma diminuição das intervenções equivocadas que geram uma diminuição do fator de segurança das encostas, podendo levar a ocorrência de deslizamentos até mesmo fora do período chuvoso.

\section{REFERÊNCIAS}

ALHEIROS, M. M.; SOUZA, M. Â. A.; BITOUN, J; MEDEIROS, S. M. G. M.; JÚNIOR, W. M. A. Manual de Ocupação dos Morros da Região Metropolitana do Recife. Fundação de Desenvolvimento Municipal FIDEM; coord. Margareth Mascarenhas Alheiros... (et al.). - Recife: Ensol, 2004.

COUTINHO R. Q; BANDEIRA, A. P. N. Processos de instabilização de encostas e avaliação do grau de risco: estudo de caso da cidade do Recife e Camaragibe. In: LACERDA, W. A. et al. (Org.). Desastres naturais: suscetibilidade e riscos, mitigação e prevenção, gestão e ações emergenciais. Rio de Janeiro: Coppe/UFRJ. 2012, 211 p.

CHOU, S. C. Análise de distúrbios ondulatórios de leste sobre o Oceano Atlântico Equatorial Sul. 1990. 153 f. Dissertação (Mestrado em Meteorologia) - Instituto Nacional de Pesquisas Espaciais, São José dos Campos, SP, 1990. Disponível em: <http://urlib.net/sid.inpe.br/MTC-m12@ 80/200>. Acesso em: 26 jun. 2011.

GALVÃO D.C. Uma contribuição para o entendimento dos fatores que provocam deslizamentos nos morros do Grande Recife: O relevo, a ocupação e o clima. Revista Humanae (Recife), v. 08, p. 1, 2014.

GUIDICINI, G.; NIEBLE, C. M. Estabilidade de taludes naturais e de escavação. São Paulo: E. Blucher. 1984. 194 p.

MENDONÇA, F.; DANNI-OLIVEIRA, I. M. Climatologia: noções básicas e climas do Brasil. São Paulo: Oficina de Textos, 2007. 206p.

MOLION, L. C. B.; BERNARDO, S. O. Uma revisão da dinâmica das chuvas no Nordeste do Brasileiro. Revista Brasileira de Meteorologia, v. 17, n. 1, 1-10, 2002. 
SILVA, V. P. Distúrbios ondulatórios de leste: estudo de casos que afetaram a costa leste do NEB. 2010. 77 f. Dissertação (Mestrado em Meteorologia) - Centro de Tecnologia e Recursos Naturais Unidade Acadêmica de Ciências Atmosféricas, Universidade Federal de Campina Grande, Campina Grande, JP, 2010.

Recebido em: 13/04/2019

Aceito para publicação em: 25/05/2019 